\title{
SYMPOSIA OF THE INTERNATIONAL ASTRONOMICAL UNION
}

I. Co-ordination of Galactic Research EDITED BY A. BLAAUW

3. Non-Stable Stars EDITED BY G. H. HERBIG

4. Radio Astronomy EDITED BY H. C. VAN DE HULST

5. The Large-Scale Structure of the Galactic System EDITED BY N. ROMAN

6. Electromagnetic Phenomena in Cosmical Physics EDITED BY B. LENHERT 


\title{
TRANSACTIONS OF THE
}

\section{INTERNATIONAL ASTRONOMICAL UNION VOLUME IX}

\author{
EDITED B Y \\ P. TH. OOSTERHOFF
}

The ninth volume of Transactions of the International Astronomical Union contains reports on the ninth General Assembly of the Union in Dublin, in Aug.-Sept. 1955. Part I records the ceremonial opening and the two sessions of the General Assembly; the report of the Executive Committee over the years $1952-4$ is reproduced. The resolutions adopted by the assembly are listed in Part II, and Part III contains the draft reports and the reports of the meetings of thirty-nine standing commissions. This part of the volume gives a survey of all astronomical activities during 1952-4. During the assembly joint discussions were held on solar flares, fundamental stars, photoelectric image tubes and their astronomical applications, and turbulence in stellar atmospheres: reports on these scientific meetings will be found in Part IV. Part V lists the standing commissions and members of the Union.

\section{CAMBRIDGE UNIVERSITY PRESS}

Bentley House, 200 Euston Road, London, N.W. I

American Branch: 32 East 57th Street, New York 22, N.Y. 